\title{
ARTEFATOS DE CUIDADO COMO EXPRESSÃO DE PODER ${ }^{1}$ CARE ARTIFACTS AS AN EXPRESSION OF POWER ARTEFACTOS DE CUIDADO COMO EXPRESIÓN DE PODER
}

\author{
Ivani Bueno de Almeida Freitas², Stela Nazareth Meneghel ${ }^{3}$
}

\begin{abstract}
${ }^{1}$ Esta pesquisa é parte da dissertação de mestrado intitulada "A construção do cuidado em um programa de atendimento domiciliar ao acamado do município de Porto Alegre, RS”, defendida em 05/07/07, no Programa de Pós-Graduação em Saúde Coletiva da Universidade do Vale do Rio dos Sinos

${ }^{2}$ Mestre em Saúde Coletiva, Professora do Curso de Enfermagem da Universidade do Vale do Rio dos Sinos. Rio Grande do Sul, Brasil.

${ }^{3}$ Doutora em Medicina, Professora do Programa de Pós-Graduação em Saúde Coletiva da Universidade do Vale do Rio dos Sinos. Orientadora da dissertação. Rio Grande do Sul, Brasil.
\end{abstract}

PALAVRAS-CHAVE: Idoso. Assistência domiciliar. Poder (Psicologia)

KEYWORDS: Aged. Home nursing. Power (Psychology)

PALABRAS CLAVE: Anciano. Atención domiciliaria de salud, Poder (Psicología).
RESUMO: Estudo de Caso, cujo objetivo principal foi de compreender a construção do cuidado no Programa de Atendimento Domiciliar ao Acamado, de uma Unidade Básica de Saúde, em Porto Alegre - RS. Dados coletados em 13 encontros de grupo com 29 cuidadores e nos domicílios, através de observação participante, de maio a dezembro/2006 e analisados através da análise do discurso. As cadeiras destinadas ao conforto do paciente no domicílio e a sonda nasoentérica foram identificadas como dispositivos de poder, nas relações dos cuidadores. A cadeira simboliza o tensionamento de poder cambiante, ora presente naquele que realiza o cuidado, ora naquele que está postado na cadeira. A sonda nasoentérica significa sofrimento e limitação imposta ao outro, mas também a preservação da vida. Referenciais pautados em Foucault, que remete à questão do homem como o que faz e exerce poder, porém sem dúvida, aponta que o poder pode produzir liberdade.

ABSTRACT: The main objective of this case study was to understand the care construction in the Home Care Program for the Bedridden (Programa de Atendimento Domiciliar ao Acamado) from a Basic Health Care Unit in Porto Alegre, RS, Brazil. Data was collected from 13 group meetings with 29 caretakers and participating observation registered in field diaries in the homes from May to December, 2006 and analyzed through discourse analysis. The chairs destined to patient comfort in their homes and the naso-enteral tube were identified as expressions of power in relationships with the caregivers. The chair symbolizes a relationship of changing power, sometimes present in the person who performs care, sometimes in the person who is placed in the chair. The nasoenteral tube signified suffering and limitation imposed on the other. References are based on Foucault, which refer to the question of man as a creator and exerciser of power, but without a doubt point out that power may produce freedom

RESUMÉN: Estudio de Caso cuyo objetivo principal fue comprender la construcción del cuidado en un Programa de Atención Domiciliar al Enfermo en Cama, en una Unidad Básica de Salud, en la ciudad de Porto Alegre - RS. Los datos fueron recolectados en 13 reuniones de grupo con 29 cuidadores, y a través de la observación participante en los hogares, siendo registrada en Diarios de Campo, en el período de mayo a diciembre de 2006, utilizándose para ello, el análisis del discurso. La sillas usadas para el confort de los enfermos y el equipo nasoentérico fueron identificados como dispositivos de poder para los cuidadores. La silla simboliza el tensionamento de poder entre el que cuida y el que está acostado en ella. La sonda nasoentérica significó sufrimiento y limitaciones impuestas al otro, pero también la preservación de la vida. Foucault nos remite al tema del hombre como el que hace y ejerce poder, pero nos muestra, sin embargo, que el poder también puede producir libertad.
Ivani Bueno de Almeida Freitas

Endereço: Rua Carvalho Monteiro, 446/ 403

90.470-100 - Porto Alegre, RS, Brasil.

E-mail: ivanifreitas@terra.com.br
Artigo original: Pesquisa Recebido em: 15 de outubro de 2007 Aprovado final: 21 de maio de 2008 


\section{INTRODUÇÃO}

Nos estabelecimentos municipais de saúde, diante do desafio de construção do Sistema Único de Saúde (SUS), vêm sendo organizados os serviços de acordo com as potencialidades e a demanda da população. Desta forma observa-se, de modo cada vez mais incisivo, a produção de arranjos gerenciais dos serviços, de acordo com a realidade de cada região.

O novo desenho da pirâmide populacional brasileira acarretou uma série de conseqüências sociais, culturais e epidemiológicas. A rápida transição nos perfis de saúde, com predomínio das enfermidades crônicas não transmissíveis, e a importância crescente de fatores de vulnerabilidade para a saúde, têm requerido, dos profissionais, da sociedade e do Estado ações preventivas e curativas.

O número de idosos, no Brasil, é superior a 18 milhões, passando a representar $10 \%$ da população, sendo que houve um crescimento de 5 milhões de pessoas nesta faixa etária, no período de 1995 a $2005 .^{1}$

O município de Porto Alegre - RS possui uma divisão territorial em saúde composta de oito Gerências Distritais. A região noroeste da cidade é considerada a segunda mais populosa em idosos $29.933(2,2 \%)$, no ano, de acordo com o censo IGBE no ano 2000. É nesse território que se insere a Unidade Básica de Saúde (UBS)

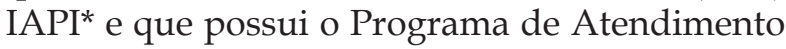
Domiciliar ao Acamado (PADA). Introduzido no rol de modalidades de atendimento da UBS, em 2003, por demanda da população. Devido às características da população moradora da área de atuação da UBS/IAPI, o PADA vem atendendo idosos, na sua maioria.

Em 2006, foi realizado um estudo sobre o PADA, buscando compreender os significados do cuidado para os cuidadores, sendo desenvolvido pelas autoras no curso de Pós-Graduação em Saúde Coletiva, da Universidade Vale do Rio dos Sinos e parte dos resultados foi usada na elaboração deste artigo. Uma das etapas do trabalho foi a nucleação de uma atividade, em grupo, para os cuidadores, a partir da constatação da necessidade de dar apoio a esses sujeitos. Eram cuidadores primários (aqueles que assumem a principal responsabilidade pelo paciente) e secundários, sendo a maioria mulheres, idosas, e familiares e havendo, ainda, a participação da equipe de saúde. ${ }^{2,3}$

O levantamento das características dos usuários do PADA mostrou que 41 eram mulheres e 20 homens, a maioria na faixa etária dos 80 aos 89 anos e apresentavam grau de incapacidade severa (não caminhavam, apresentavam incontinência habitual, necessitavam de auxílio para atividades básica e instrumental de vida diária). Verificou-se que as doenças mais comuns foram as cardiovasculares, seguidas de doença de Alzheimer/ demência, depressão e esquizofrenia, sendo que o sofrimento mental é a situação que mais causa estresse aos cuidadores.

As características das pessoas acamadas, a necessidade de reorganização familiar pelos contextos socioeconômicos da modernidade e de vida de cada família ${ }^{4}$, a situação de estresse dos cuidadores familiares, evidenciada nas visitas, foram indicadores da situação de vulnerabilidade desses sujeitos, reforçando a percepção da equipe de saúde, no sentido de propor um espaço de cuidado aos cuidadores. Este cenário impulsionou a adoção do trabalho em grupo, como estratégia educativa e de cuidado. O objetivo principal deste estudo foi o de compreender a construção do cuidado no Programa de Atendimento Domiciliar ao Acamado de uma Unidade Básica de Saúde em Porto Alegre - RS.

\section{O CUIDADO DOMICILIAR COMO DIS- POSITIVO}

Assistência tradicionalmente remete à idéia de que existe "quem assiste" e "quem é assistido". Na conformidade do modelo de atenção que caracteriza o SUS, com ações abrangentes, múltiplas, não considerando o usuário um excluído, a assistência, nesse contexto, não confere aos assistidos a característica de passividade e a proposta é de substituir assistência domiciliar por cuidado domiciliar. ${ }^{5}$

No Brasil, a experiência de cuidar, em uma abordagem domiciliar, iniciou no Rio de Janeiro, em 1919, pelo Serviço de Enfermeiras Visitadoras e, mais adiante, pelo Serviço Médico Domiciliar de Urgência, em 1949, passando a ser incorporado pelo Instituto Nacional de Previdência Social, em 1967. Outra experiência foi a da Fundação Serviço Especial de Saúde Pública, criada em 1960 e extinta em 1990, havendo alguma semelhança com o modelo assistencial do Programa da Saúde da Família, pois

\footnotetext{
* Esta sigla significa Instituto de Aposentadoria e Pensão dos Industriários, denominação mantida pelo município à UBS devido a história do território onde se insere a Unidade de Saúde, porém, está em desuso.
} 
a abordagem de atendimento era familiar, destacando que o foco desta modalidade de atendimento se concentrava nas puérperas e recém-nascidos. ${ }^{6,7}$

A legislação brasileira tem considerado a necessidade da população e sua aceitação quanto a esse modo de abordagem em Saúde Pública. O Ministério da Saúde publicou a portaria GM/ MS No 2.416, de 23 de março de 1998, ${ }^{8}$ em que se estabeleciam requisitos para o credenciamento de hospitais e critérios para a internação domiciliar no SUS; e mais recentemente a Portaria No 11/2006 da Agência Nacional de Vigilância em Saúde (ANVISA), na qual são indicadas disposições sobre o Regulamento Técnico de Funcionamento de Serviços que prestam Atenção Domiciliar noSUS, ${ }^{9}$ em serviços públicos e privados de internação e assistência domiciliar. Estas medidas da legislação brasileira vêm estabelecer critérios e qualificar a Assistência Domiciliar (AD) no território nacional.

A experiência brasileira com a AD é focada em situações específicas, e construída de acordo com as necessidades da clientela. A assistência vem sendo feita de forma fragmentada, pela iniciativa pública e privada, dividindo-se em AD, internação domiciliar e visita domiciliar, sendo ainda incipientes as iniciativas hierarquizadas e regionalizadas para todo um território. A visita domiciliar se caracteriza pela ida da equipe de saúde ao domicílio do usuário com o objetivo de avaliar suas necessidades e as de sua família, considerando a disponibilidade do serviço, constando de plano assistencial e orientações. Atendimento domiciliar pressupõe ações mais complexas, exigindo técnica e periodicidade de atendimento, pela equipe de saúde, no domicílio do usuário, de acordo com as necessidades evidenciadas. Já a internação domiciliar requer recursos mais sofisticados, incluindo os equipamentos, medicamentos, pessoal, ou seja, mínimos recursos hospitalares, exigindo baixa densidade tecnológica. ${ }^{7}$

Os Programas de Internação Domiciliar (PIDs) contribuem para uma nova lógica na atenção à saúde e na humanização da atenção. Esses programas são mais uma estratégia de política pública de Saúde na reversão da tensão centrada em hospitais, destacando que esta prática não substitui a internação hospitalar, mas pode ser utilizada no intuito de humanizar. ${ }^{7,10}$

Nesse sentido, as práticas de saúde em programas específicos para a construção da integralidade no espaço público, emergem como movimentos e formas de vinculação para concretizar o cuidado. Nos serviços de saúde onde existe a esterilização do vínculo social, pautado pela produção, pelo resultado, pelo produto, pela ação mútua marcada pelos recursos de troca, onde a dádiva (ação que pressupõe retribuição) não encontra terreno frutífero (possibilidade de diálogos onde se estabeleçam relação de vínculo), a saúde se torna um mero produto. ${ }^{11}$

Os PIDs são espaços de construção de trabalho em equipe e uso das tecnologias leves, permitindo a emergência de ações pautadas no vínculo e na integralidade.

O termo tecnologias em saúde não deve ser confundido com equipamento, pois é caracterizado por saberes que permitem operar os recursos para a realização das finalidades perseguidas pelos atores, no campo da saúde. ${ }^{12}$ Tecnologia leve é definido como o acolhimento e o vínculo; e tecnologia dura, como condutas normatizadoras. A partir daí, ocorre a reconceitualização da premissa de recursos escassos, pois, para os autores “a tecnologia leve nunca é escassa, ela sempre é um processo em produção". 12:128

O trabalho vivo constitui uma dimensãochave que é a de sempre estar em situação de governo, em estreita relação com os sujeitos em ação e com o conjunto de teorias (caixa de ferramentas). ${ }^{13} \mathrm{O}$ agir do trabalho vivo em ato na saúde é micropolítico, operado em espaços intercessores, que se caracterizam pelas relações dialógicas do processo de trabalho do trabalhador com os processos organizacionais.

Para além dos saberes científicos, o cuidado na saúde opera com o saber tecnológico, ${ }^{12,14}$ chamando a atenção para o fato de que a tecnologia leve possibilita a reconstrução da dimensão comunicacional das Unidades de Saúde.

Diversos autores destacam ainda que rearranjos tecnológicos possam ser somados a essa pluralidade dialógica, tais como expressões artísticas da linguagem, incluindo o trabalho com linguagens corporais e outras racionalidades, ${ }^{14-15}$ assim como as práticas populares de cuidado propiciando um intenso protagonismo comunitário na reconstrução da humanização. ${ }^{16}$ Nesse cenário podem surgir e ser inventados outros dispositivos de cuidado.

A assistência domiciliar pensada como tecnologia leve, tem seu propósito basilar no cuidado, fundamentalmente na família, no vínculo, na integralidade, no uso das tecnologias leves em saúde. ${ }^{17}$

Para cuidar "[...] há que se considerar e construir projetos; há que se sustentar, ao longo do tempo, uma certa relação entre a matéria e o espírito, o 
corpo e a mente, moldados a partir de uma forma que o sujeito quer opor à dissolução, inerte e amorfa, de sua presença no mundo" 17:71 A atitude de cuidar não precisa se restringir a uma pequena e subordinada parte da tarefa das práticas de saúde, mas deve se expandir, no encontro com os sujeitos.

\section{O CAMINHO DA PESQUISA}

Este foi um estudo qualitativo, caracterizado como Estudo de Caso, que se trata de um tipo de pesquisa focada em um tópico específico e em atividades que interessam, tanto aos atores, quanto ao pesquisador, por se tratarem de fenômenos contemporâneos e que contextualizam a vida real, contribuindo "para a compreensão que se tem dos fenômenos individuais, organizacionais, sociais e políticos" ${ }^{19: 21}$ ou seja, fenômenos sociais complexos.

Com este tipo de estudo se descreve a rotina e a problemática da vida das pessoas e grupos. Exige escuta dialética dos atores sociais quando se evidenciam as mediações e contradições entre a parte e o todo, tornando a compreensão dos fatos progressiva, contínua e esclarecedora sobre seus elementos e significados. ${ }^{20}$

Os sujeitos do estudo foram os operadores de cuidados no PADA, constituídos pela equipe técnica da UBS e aqueles do domicílio (doravante denominados cuidadores domiciliares) representados por familiar ou pessoa contratada para prestar cuidados à pessoa acamada.

O projeto de pesquisa foi aprovado pelo Comitê de Ética em Pesquisa da Secretaria Municipal de Saúde de Porto Alegre - RS, sob o No 132, sendo que todos sujeitos assinaram o Termo de Consentimento Livre e Esclarecido.

A coleta de dados ocorreu em 13 encontros de grupo, com os operadores do cuidado (29 sujeitos), realizados quinzenalmente na UBS, por meio de observação participante e nos domicílios, no período de maio a dezembro de 2006 , de acordo com critérios estabelecidos no projeto de pesquisa. Esses critérios permitiram a eleição daqueles domicílios, cujos usuários eram atendidos pelo PADA, seus cuidadores participavam das atividades em grupo na UBS e a equipe entendia estarem em situação de vulnerabilidade. Para a descrição dos encontros foram utilizados dados secundários, como as anotações do relator do grupo registradas em ata e dados primários, como as gravações e transcrições realizadas pela pesquisadora, além das anotações em diário de campo. Geralmente compareceu somente um cuidador domiciliar por usuário do PADA, variando esta participação de dois a 10 participantes por encontro, estando presente, ainda, dois técnicos do Programa que se encarregavam da coordenação dos trabalhos.

O trabalho em grupo é complexo, histórico e singular. ${ }^{21}$ Esta singularidade aponta que cada grupo possui movimentos próprios, de imbricadas utopias, imagens, significações e construções. Este dispositivo foi paulatinamente desenvolvido nas Ciências Humanas e na Antropologia, a partir da temática da individualidade e da identidade pessoal. ${ }^{21}$ É nos pequenos agrupamentos que a subjetividade moderna se origina e constitui, figurando enlaces e desenlaces entre os membros do grupo e possibilitando intercâmbios, nesse acontecimento.

Assumiu-se a análise do discurso como proposta teórico-metodológica de análise embasada na perspectiva construcionista do estudo da linguagem e na produção de sentidos. ${ }^{22} \mathrm{O}$ termo construcionismo utilizado não se forma na perspectiva individualista, mas pensa o indivíduo como uma construção social. O discurso, numa perspectiva foucaultiano, é dotado de poder, ${ }^{23}$ materializado em uma enunciação. Os elementos que compõem a análise de discurso são: o discurso, o enunciado, a enunciação, o saber, o poder, o autor e a formação discursiva. Para empreender a análise de um discurso deve-se considerar e conhecer a regularidade dos fenômenos, isto é, dos eventos que estão em curso, durante sua elaboração, e os limites de probabilidade de sua emergência.

O estudo foi embasado na obra sobre o cuidado de si, de autoria do filósofo Michel Foucault, o que colaborou com a construção do conhecimento sobre o PADA. ${ }^{24}$

\section{OS ARTEFATOS DE CUIDADO E DE PODER}

Na observação participante, realizada nos domicílios, ficou evidente a utilização no espaço doméstico de um objeto de grande valor para os cuidadores - a cadeira. Nos domicílios, os cuidadores, quando recebem a equipe de saúde, preferem levar os acamados para um local da casa onde está a cadeira, destinada ao conforto do paciente. Lá, ele está preparado para receber os cuidados ou se instala para melhor ser ouvido.

A importância do artefato cadeira, do assento reservado ao acamado lembrou o trono (cajado) do faraó, descrito por Foucault como um instrumento de dar visibilidade ao poder. ${ }^{25}$ Ao cuidador 
resta o ato de dobrar-se ao outro que lá se posta, à obediência à sua vontade e à racionalidade em torno do tratamento, das rotinas e dos rituais a serem dispensados. Fica patente uma relação de poder cambiante entre as posições, ora presente naquele que realiza o cuidado, ora naquele que está postado na cadeira.

Nas sociedades orientais antigas o faraó recebia ritualmente, no dia da sua coroação, um cajado de pastor. ${ }^{25} \mathrm{O}$ artefato reunia, simbolicamente, a visão do homem capaz de abrir o caminho da felicidade, por meio da conformidade, porque estava na lei, ou pela aprovação do mérito em livrar seu rebanho dos riscos. A figura do pastor tinha ainda relação com a responsabilidade que, em sua força moral, associa todos os membros da comunidade e pela obediência mantida pela dependência individual e completa à vontade e ao poder do faraó. Foucault mostra que a obediência constituía uma virtude, em um jogo cujos elementos eram a vida, a morte, a verdade, os indivíduos, a identidade. Um jogo que tinha a ver com o sacrifício dos cidadãos. E por último, a relação de finalidade, como a que pretende colocar uma ordem, que exerce o poder, uma racionalidade que define a maneira de governar a família, os súditos, os cidadãos. ${ }^{25}$

A tecnologia pastoral foi descrita como uma tecnologia de poder, na história dos homens. ${ }^{25}$ Referia-se ao pastor de homens, a um sistema de pensamento binário controvertido, e, por fim, a uma metodologia que buscou caracterizar a tarefa do pastor. Menciona que a reivindicação de legitimidade do título de pastor tinha um caráter político porque qualquer cidadão poderia reivindicá-lo, como o padeiro, que proporciona o alimento à humanidade, o médico, que cuida dos enfermos, o ator de bonecos, que guia a música, "[...] si queremos descubrir lo que es real y esencialmente el político, deberemos apartarlo de la multitud que lo rodea y demostrar así por qué no es un pastor" ${ }^{\prime 25: 108-9}$ Finalmente, expõe que a real arte de governar consistia em reunir os humanos em comunidade sob a amizade e a concórdia. O estudo foucaultiano do problema pastoral aponta para as relações de poder do Estado.

Em um domicílio, enquanto a equipe de saúde se distribuía nos afazeres, chegaram dois funcionários de uma loja trazendo uma caixa que continha uma cadeira de estofado sintético, de constituição grande, que conferia imponência ao ambiente. Lá foi acomodado o paciente. Um profissional da equipe fez uma observação: [...] ele parece um rei, na cadeira... e em seguida a cuidadora familiar retrucou:... e eu, uma escrava..., expondo a relação polarizada, presente na relação cuidador-cuidado.

Noutro domicílio, a equipe de saúde chegou para a avaliação trimestral da paciente que vindo para a sala, logo se instala em sua cadeira. Uma cadeira estofada, com apoio para os braços, mas típica do uso em ambiente comercial, usualmente vista em gabinete do chefe de seção. Os filhos a rodeiam e parte da equipe de saúde se posta à sua frente. Conforme a paciente falava, os filhos, por vezes, interrompiam, de forma discreta. De seu lugar, a paciente ordenava o ritmo do ambiente, fazia um filho buscar algo no quarto, outro, ao seu comando, seguia para a cozinha, mas quando era a vez da nutricionista falar se calava, porém não deixava de impor seu pensamento. Depois da visita a própria nutricionista comentou: [...] A $D$. parece um general; do seu posto, comanda a todos.... O cenário se assemelhava ao gabinete de um chefe, deixando explícita a relação de poder do paciente acamado em relação à família.

Nos encontros em grupo, outro artefato gerador de discussão entre os cuidadores e equipe de saúde foi a sonda nasoentérica. Alguns usuários acamados utilizaram a sonda e os cuidadores já haviam vivido alguma experiência com esse objeto que os marcou emocionalmente, enquanto para a equipe de saúde tratava de uma discussão ética.

Uma das cuidadoras relatou uma experiência negativa com o uso da sonda, relacionada à hospitalização de uma religiosa cega, que pela situação de cegueira não conseguia entender que estava sendo alimentada e se queixava continuamente, demonstrando sofrimento. Para um cuidador responsabilizado pela colocação da sonda em sua esposa, pelo agravamento do estado nutricional diagnosticado pela equipe de saúde, esse foi um momento de preocupação e de dor. Este caso suscitou a reflexão sobre o uso de sonda, pois se tratava de uma necessidade, mas que exigiria a contenção da única parte de corpo da acamada que se movia - o braço direito. É notório o sofrimento do cuidador frente às situações que lhe impõem responsabilidade e manejo do cuidado aflorando sentimentos antagônicos. ${ }^{26}$

A mobilização da equipe de saúde em torno desse caso proporcionou a discussão sobre a necessidade da manutenção da vida e a limitação imposta ao outro; ao período de amadurecimento das mudanças impostas ao cuidador pela "nova ação de cuidado" (uso da sonda), o respeito pelos sentimentos do cuidador e a importante participação do acamado na escuta, quanto ao que se 
pretende de cuidados relativos à sua qualidade de vida, independentes de sua capacidade de entendimento. A discussão sobre o tema ainda não se esgotou, mas teve como princípio o respeito à singularidade do cuidado em saúde.

Pogrebinschi ${ }^{27}$ ao estudar a obra de Foucault sobre o poder apresenta seus elementos: a imanência, imaterialidade, múlltiplas relações de força, direito e a verdade. Sendo possível dispensar do poder sua roupagem repressiva, substituindo-o pelo seu caráter autopoiético.

\section{CONSIDERAÇÕES FINAIS}

Alguns dos dispositivos usados pelos cuidadores domiciliares no trajeto grupal em que foram acompanhados, como a cadeira do acamado e a sonda nasoentérica, revelaram a polissemia dos atos e instrumentos usados nas relações de cuidado.

A transformação na política assistencial brasileira expressa pelo movimento de humanização do cuidado, adoção de estratégias cuidadoras e políticas públicas que reconhecem o ambiente familiar como cooperador nas ações de saúde vem tensionando a cristalização do poder disciplinar e medicalizador. Embora esse fato possa ser positivo, entendê-lo na perspectiva foucaultiana remete à questão do poder e que o poder não confere uma localização privilegiada na sociedade, é sem fronteiras e limites, cambiante, podendo, assim como o cuidado, servir para subjugar ou para libertar.

\section{REFERÊNCIAS}

1 Fundação Instituto Brasileiro de Geografia e Estatística. Síntese de indicadores sociais 2006. Rio de Janeiro: IBGE; 2006.

2 Laham CF, Silva LA. O cuidador. In: Jacob Filho W, editor. Avaliação global do idoso: manual da Liga do Gamia. São Paulo: Atheneu; 2005. p.171-80.

3 Gonçalves LHT, Alvarez AM, Sena ELS, Santana LWS, Vicente FR. Perfil da família cuidadora de idoso doente/fragilizado do contexto sociocultural de Florianópolis, SC. Texto Contexto Enferm. 2006 Out-Dez; 15 (4): 570-7.

4 Gomes MA, Pereira MLD. Família em situação de vulnerabilidade social: uma questão de políticas públicas. Ciênc. Saúde Colet. 200510 (2): 357-363.

5 Candeias JAN. Assistência e atenção. Rev. Saúde Pública. 1992 Ago; 26 (4): 215-6.

6 Rehem TCMSB. Assistência domiciliar em saúde: subsídios para um projeto de atenção básica brasileira. Ciênc. Saúde Colet. 2005 Set-Dez; 10 (sup): 231-42.
7 Fabrício SCC, Wehbe G, Nassur F.B, Andrade JI. Assistência domiciliar: a experiência de um hospital privado do interior paulista. Rev. Latino-am. Enfermagem. 2004 Set-Out; 12 (5): 721-6.

8 Ministério da Saúde [página na Internet]. Brasília: MS; 1998 [atualizado 2007 May 04; acesso em 2007 May 10]. Disponível em: http:/ / dtr2001.saude.gov. br/sas/portarias/port98/GM/GM-2416.html

9 Ministério da Saúde [página na Internet]. Brasília: MS; 2006 [atualizado 2007 May 04; acesso em 2007 May 10]. Disponível em: http:/ / e-legis.anvisa.gov. br/leisref/public/showAct.php?id=20642\&word

10 Silva KL, Sena R, Leite JCA, Seixas CT, Gonçalves AM. Internação domiciliar no Sistema Único de Saúde. Rev. Saúde Pública. 2005 Jun; 39 (3): 391-7.

11 Guizardi RL, Pinheiro R. Quando a dádiva se transforma em saúde: algumas questões sobre a integralidade e o cuidado nas relações entre sociedade e Estado. In: Pinheiro R, Matos R, organizadores. Cuidado: as fronteiras da integralidade. Rio de Janeiro: Hucitec; 2004. p. 37-56.

12 Merhy EE, Chakkour M, Stéfano E, Stéfano MAE, Santos CM, Rodrigues RA, et al. Em busca de ferramentas analisadoras das tecnologias em saúde: a informação e o dia a dia de um serviço, interrogando e gerindo trabalho em saúde. In: Merhy EE, Onocko R, organizadores. Agir em saúde: um desafio para o público. São Paulo: Hucitec; 1997. p.113-50.

13 Merhy EE. Em busca do tempo perdido: a micropolítica do trabalho vivo em saúde. In: Merhy EE, Onocko $\mathrm{R}$, organizadores. Agir em saúde: um desafio para o público. São Paulo: Hucitec; 1997. p.71-111.

14 Ayres JRCM. Cuidado e reconstrução das práticas de saúde. In: Minayo MCS, Coimbra Júnior CEA, organizadores. Críticas e atuantes: ciências sociais e humanas em saúde na América Latina. Rio de Janeiro: FIOCRUZ; 2005. p.91-108.

15 Machado RRS, Pinheiro R, Guizardi FL. As novas formas de cuidado integral nos espaços públicos de saúde. In: Pinheiro R, Matos R, organizadores. Cuidado: as fronteiras da integralidade. Rio de Janeiro: Hucitec; 2004. p. 57-74.

16 Acioli S. Os sentidos de cuidado em práticas populares voltadas para a saúde e a doença. In: Pinheiro R, Matos R, organizadores. Cuidado: as fronteiras da integralidade. Rio de Janeiro: Hucitec; 2004. p. 187-203.

17 Sakata KN, Almeida MCP, Alvarenga AM, Craco PF, Pereira, MJB. Concepções da equipe de saúde da família sobre as visitas domiciliares. Rev Bras Enferm. 2007 Nov-Dez; 60(6): 659-64.

18 Ayres JRCM. Sujeito, intersubjetividade e práticas de saúde. Ciênc. Saúde Colet. 2001 Jan-Jun; 6 (1): 63-72.

19 Yin RK. Estudo de caso: planejamento e métodos. 2a ed. Porto Alegre: Bookman; 2002. 
20 Denzin NK, Lincoln YS. O planejamento da pesquisa qualitativo: teorias e abordagens. Porto Alegre: Artmed; 2006.

21 Fernández AM. El campo grupal: notas para una genealogía. 9a ed. Buenos Aires: Nueva Visión; 2001.

22 Spink MJ, Medrado B. Produção de sentidos no cotidiano: uma abordagem teórico-metodológica para análise das práticas discursivas. In: Spink MJ, organizadora. Práticas discursivas e produção de sentidos no cotidiano. São Paulo: Cortez; 1999. p.41-61.

23 Foucault M. A ordem do discurso. São Paulo: Loyola; 2000.
24 Foucault M. A hermenêutica do sujeito. São Paulo: Martins Fontes; 2004.

25 Foucault M. Tecnologías del yo y otros textos afines. 3a ed. Barcelona: Paidós Ibérica; 1996.

26 Silveira. TM da, Caldas CP, Carneiro TF. Cuidando de idosos altamente dependentes na comunidade: um estudo sobre cuidadores familiares principais. Cad. Saúde Pública. 2006 Ago; 22 (8):1629-38.

27 Pogrebinschi T. Foucault, para além do poder disciplinar e do biopoder. Lua Nova. $2004 \mathrm{n}^{\circ}$ 63: 180-201. 